\title{
Antioxidant Properties of Chinese Propolis in Ross Broilers Exposed to Heat Stress in Egypt
}

\author{
Manal A. M. Mahmoud*, Hosnia S. Abdel-Mohsein, Mohamed R. F. Farghali \\ Department of Animal Hygiene, Faculty of Veterinary Medicine, Assiut University, Assiut, Egypt \\ Email: ${ }^{*}$ egymanal@gmail.com, ${ }^{*}$ manalmahmoud@vet.au.edu.eg
}

Received 17 August 2015; accepted 19 September 2015; published 22 September 2015

Copyright (C) 2015 by authors and Scientific Research Publishing Inc.

This work is licensed under the Creative Commons Attribution International License (CC BY). http://creativecommons.org/licenses/by/4.0/

(c) (i) Open Access

\begin{abstract}
Detrimental effects of heat stress that causes great loss to poultry industry have grown the global attention for the importance of natural antioxidant in alleviating the oxidative stress symptoms in poultry. The antioxidant effect of Chinese ether extract propolis (EEP) on broilers (Ross 308) exposed to chronic heat stress has been evaluated. Eighty broilers (15 days old) were randomly allocated into five equal groups; each received a maintenance diet supplemented by vitamin C ( 250 $\mathrm{mg} / \mathrm{kg}$ diet) or propolis $(250,500$ and $750 \mathrm{mg} / \mathrm{kg}$ diet) or not supplemented (control) for $27 \mathrm{con}$ secutive days. Blood samples were collected to analyze serum corticosteron, total antioxidant capacity (TAC) and lipid peroxidation activity (MDA) at the end of the experiment. Moreover, the active chemical components responsible for the biological activities of EEP have been determined using Gas Chromatography/Mass Spectrometry (GC/MS). Results revealed a significant decrease in corticosterone levels in broilers after vit $\mathrm{C}$ or EEP supplementation. This improvement is parallel to a significant increase in TAC and decrease in MDA in broilers after EEP supplementation, which may be due to its high flavonoid content. Results show that Chinese EEP has biologically active compounds responsible for excellent antioxidant activities that ameliorate the negative impacts of elevated temperature in summer season in Egypt.
\end{abstract}

\section{Keywords}

Propolis, Total Antioxidant, Corticosterone, Poultry

\section{Introduction}

Heat stress is a cause of great concern among poultry producers as it leads to decrease production with devastat-

\footnotetext{
${ }^{*}$ Corresponding author.
}

How to cite this paper: Mahmoud, M.A.M., Abdel-Mohsein, H.S. and Farghali, M.R.F. (2015) Antioxidant Properties of Chinese Propolis in Ross Broilers Exposed to Heat Stress in Egypt. Open Journal of Veterinary Medicine, 5, 197-209. 
ing economic consequences to poultry industry, especially in subtropical and tropical countries. In Egypt, summer and early autumn seasons (from May to September) are not within the thermo neutral zone [1]. The ambient air temperature can remain consistently high for extended time $\left(40^{\circ} \mathrm{C}\right)$ with high relative humidity. High mortality, decreased feed intake, lower body weight gain and poor feed efficiency as well as atrophy of the spleen, thymus, and bursa of Fabricius, are common adverse effects of heat stress in broiler chickens [2]-[4]. Hormonal and metabolic changes are also implicated in response to prolonged or chronic exposure to heat stress. Heat stress has the potential to activate the neuroendocrine system and hypothalamic-pituitary-adrenal (HPA) axis, resulting in increasing serum and plasma corticosterone levels [5]. Generally, corticosteroid concentrations in blood have been used as an indicator of environmental stress in birds [6] [7]. Higher levels of circulating corticosteroids deteriorate the animal's health status [8] through muscle wasting and retarded growth [9].

Heat stress could be responsible for releasing the reactive oxygen species (ROS), the major culprits for causing oxidative stress, if their level exceeds the threshold value [10]. The imbalance or loss of cellular redox homeostasis causing severe damage to cellular components [11] and promote damage to essential biomolecules such as carbohydrates, proteins, amino acids, lipids and nucleic acids [12]-[15]. As a consequence of increased free radical generation, lipid peroxidation could be increased. The rise of lipid peroxidation increased the malondialdehyde level in blood and tissues [16]. Lipid peroxidation can compromise the integrity of cell membranes and increase cell membrane fluidity, which adversely affects immune responses. They trigger progressive destruction of polyunsaturated fatty acids (PUFA), ultimately leading to membrane destruction [10].

Dietary modifications are among the most preferred and practical ways to alleviate the effect of high environmental temperature in poultry [17]. Antioxidants are agents that scavenge ROS, prevent their formation, or repair the damage they cause [18]. Antioxidants are effective because they are capable to donate their own electrons to free radicals. When a free radical gains the electron from an antioxidant, it no longer attacks the cell and the chain reaction of oxidation is broken [19]. Supplementation of vitamin C, L-ascorbic acid, is perhaps the most famous form of antioxidant available. Vitamin $\mathrm{C}$ is a chain breaking antioxidant, well known to provide necessary defense against oxidative stress because of their anti-stress effects to poultry [20]-[22]. Reduction in blood corticosterone level [23] [24] and attenuated lipid peroxidation [16] were also reported.

Recently, there has been a growing interest in the discovery of natural antioxidants for use as substitution for synthetic antioxidants, which has been restricted because many of them have carcinogenic potential [25] [26]. Propolis can be considered as a candidate alternative for providing powerful antioxidant protection for the body. It has been used for folk medicine and foods since ancient times in many parts of the world [19]. Propolis is an adhesive, dark yellow to brown colored balsam that smells like resin. It is collected from the buds, leaves and similar parts of trees and plants by bees and mixed with their wax [21] [27]. More than 300 constituents have been identified in different propolis samples [28]; mostly include a mixture of polyphenols, flavonoid aglycones, phenolic acid and their esters, and phenolic aldehydes and ketones, terpenes, sterols, vitamins and amino acids [29]. Several biological properties such as antibacterial and antifungal [30], antiviral [31], anti-inflammatory [32], antitumor [33] and immunomodulatory [34] may be attributed to the variety of chemical compounds identified in propolis.

The biological potential of propolis could be due to a synergism that occurs among their constituents [35]. There is a correlation between the high content of total flavonoids and the anti free radical activity in propolis extracted from Argentina [36]. Da Silva et al., 2006 [37] suggested that the flavonoids play an important role in the antioxidant activity of Brazilian propolis extracts, but that other compounds could be involved [38]. Several investigations on propolis in Eastern Europe and South America have showed that flavonoids concentrated in propolis are powerful antioxidants which are capable to scavenge free radicals [39] [40]. Flavonoids and various phenolics in propolis have been appeared to be capable of scavenging free radicals and thereby protecting lipids and other compounds from being oxidized or destroyed during oxidative damage [16]. Besides, flavonoids inhibit lipid peroxidation, platelet aggregation, capillary permeability and fragility [41].

Recently propolis is the most important dietary supplement as antioxidant compound because of their anti stress effects [42] [43]. Furthermore, propolis can relieve the adverse effects of lipid peroxidation and free radical formation [16] [44]. The antioxidant activities of propolis of various geographic origins such as Argentina, Australia, Brazil, China, and United States were confirmed in vitro by the presence of strong antioxidant activity [45].

However, because of the vast biodiversity of China, different composition resulted from diverse botanical origin of Chinese propolis are needed to be identified. Also, there are a few data about using of Chinese ether extract propolis as natural feed additive to broiler diets for alleviating the metabolic and hormonal changes resulted 
from heat stress. Therefore, the purpose of the present study was to determine the chemical composition and the antioxidant activity of ether extract of propolis against free radicals generation in Ross broilers in summer season in Egypt.

\section{Materials and Methods}

\subsection{Birds, Diet and Experimental Design}

The experiment was conducted in accordance with animal welfare. A total of eighty, one-day old, unsexed broiler chicks (Ross 308) were randomly allocated to 5 experimental groups according to their initial body weights. Ross 308 chicks were purchased from Katkoot Al Wadi, a company of Wadi group, Egypt. Each treatment consisted of 16 birds per pen and all pens were bedded with clean, soft wood-shavings litter materials. Broiler chickens were housed in environmentally controlled floor house system and had ad libitum access to feed and water through feeders and drinkers. Chicks were fed as follows: 1-Control group; basal diet with no additives, 2-Basal diet supplemented with $250 \mathrm{mg}$ Chinese ether extracted propolis (EEP)/kg diet, 3-Basal diet containing $500 \mathrm{mg}$ EEP/kg diet, 4—Basal diet containing $750 \mathrm{mg} \mathrm{EEP} / \mathrm{kg}$ diet, 5—Basal diet containing $250 \mathrm{mg}$ ascorbic acid (Vit C)/kg diet. The addition of EEP and vit $\mathrm{C}$ to the diet was started at day 15 till the end of the experiment (42 days). Small amounts of the basal diet were first mixed with the respective amounts of EEP or vit $C$ as a small batch and then with a larger amount of the basal diet, until the total amount of the diets were homogeneously mixed. Birds were given a starter diet to 21 days of age followed by a grower diet till the end of experiment (42 days). The ingredients of the starter, grower diet and calculated energy uptake/Kg diet are presented in Table 1. Diet was formulated to meet nutrient recommendations according to the National Research Council of the US [46]. Birds were reared at a density of $20 \mathrm{~kg} / \mathrm{m}^{2}$ with a lighting program of 23 hours lightning and 1 hour darkness per day. Birds were given a starter diet until 21 days of age followed by a grower diet till the end of experiment (42 days). During the experimental period from 15 to 42 days of age, the indoor temperature was $38 \pm 1.4^{\circ} \mathrm{C}$, while the relative humidity was $49 \% \pm 2 \%$. The heat source was provided by electrical heaters if the temperature decreases at night. Each broiler chicken was vaccinated against Newcastle Disease Virus (NDV) via drinking water at 6, 14, 21, and 32 days of age, and against Infectious Bursal Disease (IBD) at 10,18 and 25 days of age.

\subsection{Propolis and Its Analysis}

EEP was purchased from Dalian Tianshan Industrial Co. ${ }^{\mathrm{TM}}$, Ltd. Changjiang Road, Dalian, Liaoning, China. Propolis was analyzed by Gas chromatography-mass spectrometry to detect its main components.

Table 1. Composition of the experimental diets $(\mathrm{g} / \mathrm{kg})$ and energy uptake $(\mathrm{Kg} / \mathrm{diet})$.

\begin{tabular}{ccc}
\hline Ingredients & Starter & Grower \\
\hline Corn & 50.5 & 60.05 \\
Fish meal & 3.5 & 3 \\
SBM & 36.75 & 29 \\
Sunflower oil & 6 & 4.7 \\
Dicalcium phosphate & 1.5 & 1.5 \\
Ground lime stone & 1 & 1 \\
Salt & 0.3 & 0.3 \\
Lysine & 0.1 & 0.1 \\
Methionine & 0.1 & 0.1 \\
Premix & 0.25 & 0.25 \\
Calculated energy uptake/Kg diet & Starter & Grower \\
E (Kcal/kg) & 3202.465 & 3208.048 \\
\hline
\end{tabular}


Sample preparation and identification

Preparation of propolis sample was done according to [47]; $2.5 \mathrm{mg}$ of the dried EEP was prepared for chromatography by derivatization for $30 \mathrm{~min}$ at $100^{\circ} \mathrm{C}$ with $50 \mu \mathrm{l}$ pyridine $+100 \mu \mathrm{l}$ bis(trimethylsilyl)tri-fluoracetamide (BSTFA) and analyzed by Gas Chromatography/ Mass Spectrometry (GC/MS). The GC/MS analysis was performed, at the Analytical Chemistry Unit, Faculty of Science, Assiut University, using Agilent Gas Chromatograph Series 7890A linked to Agilent 5975B Inert XL MSD mass spectrometer system (Agilent, USA) equipped with a DB-5MS column ( $30 \mathrm{~mm} \times 0.25 \mathrm{~mm}, 0.25 \mu \mathrm{m}$ film thickness). GC condition: splitless injection mode (40s). Helium was used as the carrier gas at a flow rate of $10 \mathrm{~mL} / \mathrm{min}$. The temperature program was: initial temperature $80^{\circ} \mathrm{C}\left(1 \mathrm{~min}\right.$ hold) and up to $280^{\circ} \mathrm{C}\left(6^{\circ} \mathrm{C} / \mathrm{min}\right)$ with $15 \mathrm{~min}$ hold. Column interface $\mathrm{T} 280^{\circ} \mathrm{C}$ and ionization source $\mathrm{T} 250^{\circ} \mathrm{C}$. The mass spectra were recorded in electron ionization (EI) mode at $70 \mathrm{eV}$.

The identification compounds were accomplished using computer searches on Wiley \& NIST MS data library using MSD ChemStation software G170EA E.02.01.1177. The components of propolis were characterized by its retention time (RT) and determined by considering their areas as percentage of the total ion current (Figure 1). Nineteen chemical compounds were identified from the Chinese ether extracted propolis by GC-MS analysis (Table 2); they represent a total area of $100 \%$.

\subsection{Blood Samples Collection and Analysis}

At the end of the experiment (day 42), five birds were randomly selected from each treatment, slaughtered and then blood samples were collected in centrifuge tubes without anticoagulant. Blood samples were centrifuged at $3000 \mathrm{rpm}$ for $10 \mathrm{~min}$, and then serum was collected and stored at $-20^{\circ} \mathrm{C}$ for later analysis. Total antioxidant capacity, lipid peroxidation and serum corticosterone concentrations were determined. The tests were performed by Digital-VIS/ultraviolet spectrophotometer (Cecil instruments, Cambridge, England, Series No. 52.232) in the laboratory at the Department of Animal Medicine, Assuit University, Egypt

Serum corticosterone concentrations were determined using commercially available Assay Max Corticosterone ELISA kits according to the procedures described by manufacture (Assay pro LLC Saint Charles, Missouri, USA).

Total antioxidant capacity (TAC) and lipid peroxidation (Malonaldialdehyde) were estimated using TAC and MDA Colorimetric Assay Kits, respectively. TAC and MDA Colorimetric Kits were supplied by Bio-Diagnostics Company (Bio-Diagnostics Company, Cairo, Egypt).

The total antioxidant capacity was performed by the reaction of antioxidants in the sample with a defined

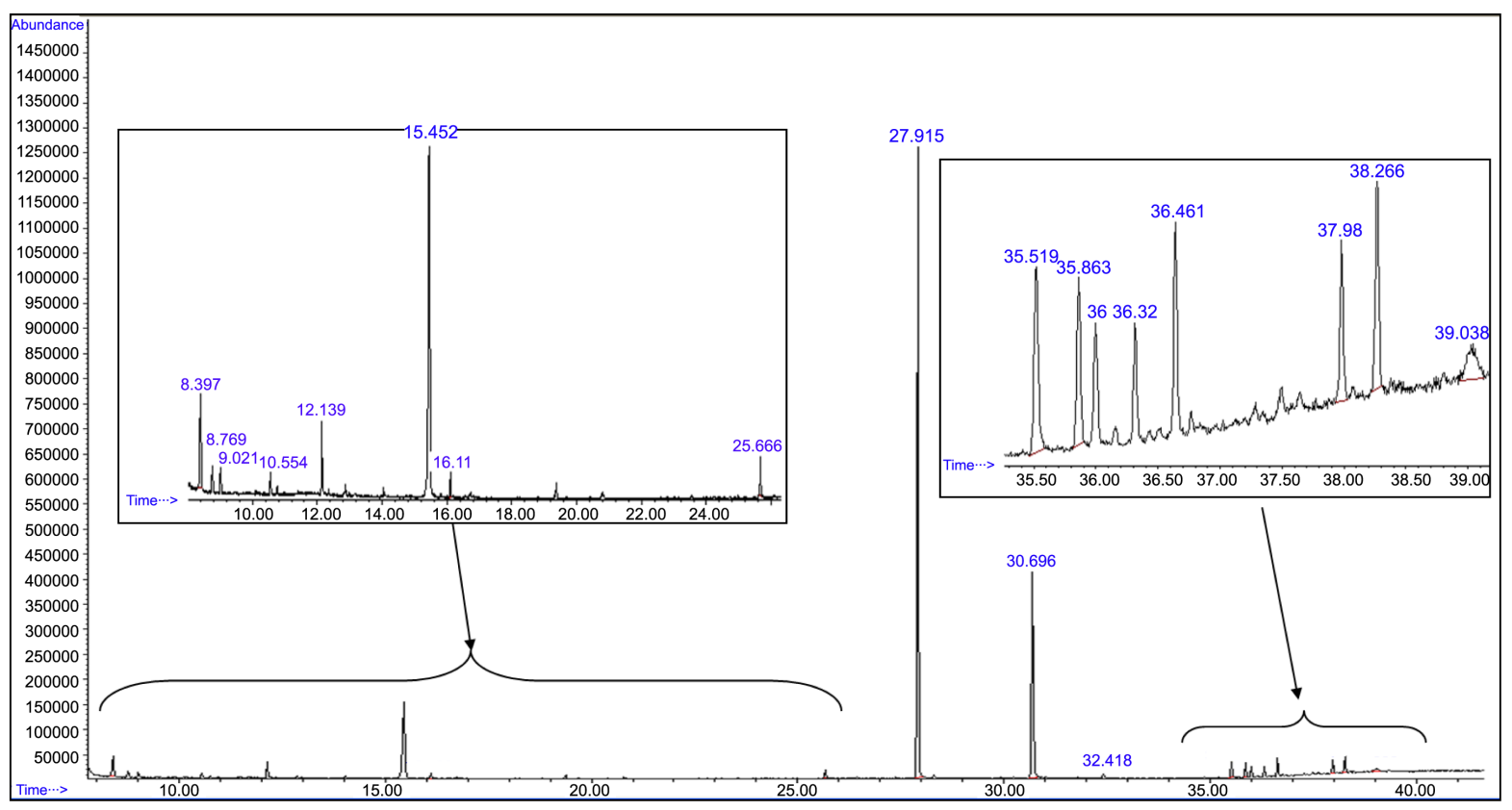

Figure 1. GC/MS chromatogram of Chinese EEP. 
Table 2. Chemical analysis of EEP propolis bioactive components by GC/MS.

\begin{tabular}{|c|c|c|c|}
\hline Comp No. & $\mathrm{RT}(\min )$ & Compound name & Peak area \% \\
\hline 1 & 8.397 & 2-Methyl-thieno[2',3':3,4]benzo[2,1-d]thiazol-5-ol & 2.4 \\
\hline 2 & 8.769 & 5,7-dihydroxy-4-chromenone (Luteolin) & 0.7 \\
\hline 3 & 9.021 & 2-Propenoic acid, 2-[(trimethylsilyl)oxy]-, trimethylsilyl ester & 0.6 \\
\hline 4 & 10.554 & p-(Dimethylamino)cinnamic acid & 0.5 \\
\hline 5 & 12.139 & 3,5,7-trihydroxy-2-phenylchromen-4-one (Galangin) & 1.1 \\
\hline 6 & 15.452 & 3-Acetyl-2-methyl-6-phenyl-4H-pyran-4-one & 11.7 \\
\hline 7 & 16.11 & (E)-3-phenylprop-2-enoic acid (cinnamic acid) & 0.3 \\
\hline 8 & 25.666 & Benzene, (2-methyl-1-propenyl)- & 0.8 \\
\hline 9 & 27.915 & Flavanone, 5,7-dihydroxy, mono-TMS* & 46.9 \\
\hline 10 & 30.696 & 3-O-[(S)-2-Methylbutyroyl] pinobanksin ${ }^{*}$ & 25.4 \\
\hline 11 & 32.418 & $\begin{array}{c}\text { (2R,3R)-3-(Acetyloxy)-2,3-dihydro-5,7-dihydroxy-2-phenyl-4H-1-benzopyran-4-one } \\
\text { (Pinobanksin acetate) }\end{array}$ & 0.8 \\
\hline 12 & 35.519 & 3,5,4'-tri-O-methyl-7-O-(trimethylsilyl) kaempferol & 1.6 \\
\hline 13 & 35.863 & Chalcone, 2',4',6'-trihydroxy-4-methoxy, tris-TMS & 1.3 \\
\hline 14 & 36 & 2'-Acetyl-1'-(1,2-dihydroquinoxalin-2-yl)-1',2'-dihydroquinoline & 0.9 \\
\hline 15 & 36.32 & 1,3-Dihydro-2-methyl-1,3,2-naphtho[1,8-cd]diazaphosphole-2-oxide* & 0.8 \\
\hline 16 & 36.641 & 6-Cinnamylchrysin ${ }^{*}$ & 1.5 \\
\hline 17 & 37.98 & 2-Monopalmitin trimethylsilyl ether ${ }^{*}$ & 1.1 \\
\hline 18 & 38.266 & $\begin{array}{c}\text { Silane, ([9-(([Dimethyl(propyl)silyl]oxy)methyl)-6,6-dimethyl-3-pentyl-6a,7,8,10 } \\
\text { a-tetrahydro-6H-benzo[c]chromen }\end{array}$ & 1.6 \\
\hline 19 & 39.038 & 5-Nitrobenzofuran-2-Carboxylic Acid & 0.2 \\
\hline
\end{tabular}

"Components have similarity more than $50 \%$ of the search results by comparison with data from literature and the profiles from the Nist library.

amount of exogenously provided hydrogen peroxide $\left(\mathrm{H}_{2} \mathrm{O}_{2}\right)$. The antioxidants in the sample eliminated a certain amount of the provided $\mathrm{H}_{2} \mathrm{O}_{2}$. The residual $\mathrm{H}_{2} \mathrm{O}_{2}$ is determined colorimetrically by an enzymatic reaction which evolve the conversion of 3,5 , dichloro-2-hydroxy benzensulphonate to colored product that was measured by spectrophotometer.

Regards to Malonaldialdehyde activity, thiobarbituric acid (TBA) reacted with MDA in acidic medium at temperature of $95^{\circ} \mathrm{C}$ for $30 \mathrm{~min}$ to form thiobarbituric acid reactive product, the absorbance of this products could be measured at $534 \mathrm{~nm}$. The results of reading were expressed as mmol/l.

\subsection{Statistical Analysis}

Results were analyzed statistically using SPSS ver 16.0 for windows. The data were described using means, and standard deviations as descriptive statistics. Significant differences among treatment means were measured and compared by general linear model (GLM) and Tukey’s post hoc test. Statistical difference with $\mathrm{P}<0.05$ was considered as significant.

\section{Results and Discussion}

\subsection{Effect of EEP on Corticosterone Levels in Broilers Exposed to Heat Stress}

High environmental temperature alters the activity of the neuroendocrine system of poultry, resulting in activation of the hypothalamic-pituitary-adrenal (HPA) axis, and elevated plasma corticosterone concentrations [48] [49]. Kutlu and Forbes, 1993 [50] reported that heat stress tended to elevate plasma corticesterone concentra- 
tions and their levels according to Mahmoud et al., 2014, [51] increased by an average of 67.57\%. Similarly, it was observed that broiler chickens exposed to chronic heat stress $\left(30^{\circ} \mathrm{C}\right)$ induced a $90 \%$ increase in plasma corticosterone compared to birds kept on thermo neutral conditions $\left(20^{\circ} \mathrm{C}\right)$ [48]. Moreover, heat stress $(31 \pm 1$ and $36 \pm 1^{\circ} \mathrm{C}$ ) applied to broiler chickens from d 35 to 42 of life, increased the corticosterone serum levels (110 and $147 \%$ high, respectively) [52] accompanied by negative effects on the chickens' performance, immune function and the intestinal mucosa as consequences for the stress-induced hypothalamic-pituitary-adrenal axis activation [52].

As shown in Figure 2, a significant decrease in corticosterone level in heat stressed broilers after vit $\mathrm{C}$ supplementation $(P<0.01)$. Oxidative stress in broilers during summer could be ameliorated using synthetic vit $\mathrm{C}$ [53]. Accordingly, vit $\mathrm{C}$ was used as a positive control in this study. This finding agreed with Nockels et al., 1973 [54], Sheila and Cheryl, 1978 [55] and McKee et al., 1997 [56] who mentioned that, ascorbic acid has been widely used to reduce the stress in chickens, because this vitamin could decrease corticosterone level in the blood circulation.

Our study revealed significant decrease in serum corticosterone levels $(P<0.01)$ in all the treatment groups compared with the control. Elevated serum corticosterone levels in control group exposed to prolonged heat stress were attenuated by propolis (250, 500 and $750 \mathrm{mg} / \mathrm{kg}$ diet) and vit C (250 mg/kg diet) supplementation (Figure 2). Our results was not in accordance with Mahmoud et al., (2014) [51] who observed a non significant decrease in serum corticosterone level following supplementation of propolis at $250 \mathrm{mg} / \mathrm{kg}$ diet for broilers exposed to heat stress. In stressed mice, non significant effect of Brazilian green propolis on serum corticosterone levels was also reported by Missima and Sforcin, 2008 [34] and Pagliarone et al., 2009 [57]. The same observation was observed among the chronically stressed mice (assessing the T9oll-like receptor (TLR-2 and TLR-4) expression by spleen cells) after propolis supplementation [58].

On the contrary, reduction of corticosterone level due to propolis administration in stress condition was reported for other species than broilers. In rats, ethanolic extract of Brazilian propolis exerted a protective effect against stress induced gastric mucosal lesions indicted by decrease serum corticosterone level significantly [59]. In addition, propolis showed effects on anxiety of restraint-stressed mice trough antagonizing the hyper-function of hypothalamic-pituitary-adrenal axis resulting in decreased levels of corticosterone and improving the ability of antioxidation on brain tissue which may be possible due to propolis essential oils [60].

Oral administration of Brazilian red propolis had a significant decreased in serum cortisol level in ewes $(P<$ 0.05) which might be related to high concentration of flavonoieds [61]. Furthermore, Ohno et al., 2002 [62] showed that flavonoieds were able to inhibit significantly cortisol secretion from H295R cells and this may be related to the hydroxyl group at position 6 of pyran ring or the 4 position of the benzene ring of flavones. In isoflavones, a hydroxyl or methylxy group in the 4 position of the benzene ring inhibited cortisol production, but the glucosyl group in the 7 position on the pyran ring did not [62]. Moreover, recent studies have shown that propolis essential oil has an anxiolytic effect on an acutely stressed mouse model through modulation of the hypothalamic-pituitary-adrenal (HPA) axis [58] [63]. Abdel-Mohsein et al., 2014 [64] suggested that propolis

\section{Corticosterone}

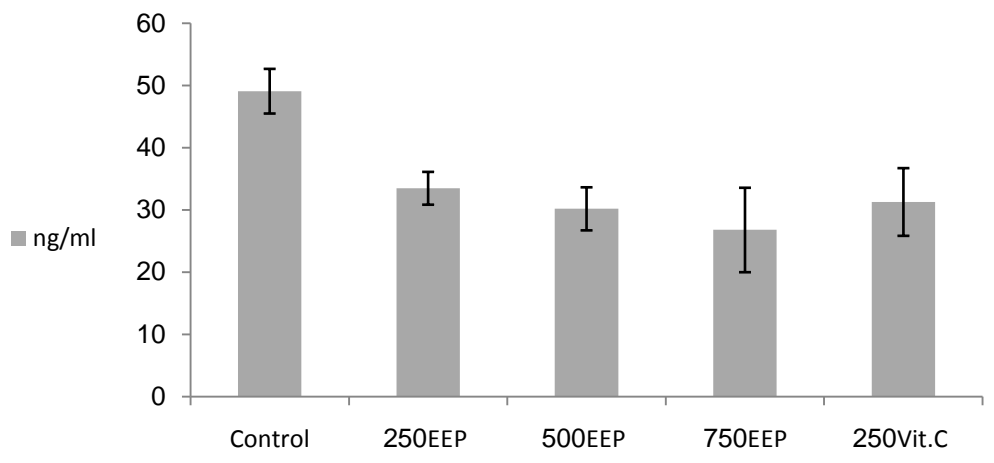

Figure 2. Effect of Chinese EEP (250, 500 and $750 \mathrm{mg} / \mathrm{kg}$ diet) and vit C (250 mg/kg diet) on corticosterone level in broilers exposed to heat stress. abc: means with different letters are significantly different $(P<0.05)$. 
supplementation could improve the HPA axis and reduce the blood corticosterone level, through the restoration of intestinal microbial ecology of broilers subjected to hot environment.

\subsection{Effect of EEP on Antioxidant Capacity and Lipid Peroxide in Broilers Exposed to Heat Stress}

Oxidative stress is known as the main cause of balance disturbance between cellular metabolic antioxidant and oxidant [65]. Dietary supplementations of EEP and vit C to broilers (15 - 42 days) exposed to chronic heat stress led to increase in total antioxidant capacity (TAC) and decrease the activity of lipid peroxide (malondialdehyde, MDA) level (Figure 3(a) \& Figure 3(b)). The highest and significant protective effect of EEP was achieved at concentrations of 250 and $500 \mathrm{mg} / \mathrm{kg}$ diet. However, higher concentration of EEP (750 mg/kg diet) and vit C (250 mg/kg diet) led to increase the TAC but not significantly. Meanwhile, the MDA resulted from heat stress was significantly ameliorated with EEP at concentrations of 500 and $750 \mathrm{mg} / \mathrm{kg}$ diet $(P<0.01)$. Non significant decrease in MDA level at $250 \mathrm{mg} / \mathrm{kg}$ diet for EEP or vit C was observed.

Treatment with vit $\mathrm{C}$ or propolis reduced the oxidative stress in broilers exposed to heat stress, represented by increased total antioxidant capacity and decreased activity of the malondialdehyde (MDA; the end product of lipid peroxidation) in the blood. The role of vit $\mathrm{C}$ as an antioxidant agent has been reported in several studies [66]-[68]. EEP showed very good antioxidant activity and decrease in MDA, compared to the well-known antioxidant vit C, used as a positive control.

This finding is consistent with that of previous study on propolis supplementation to rabbit bucks which could reduce the oxidative stress during the summer season, represented by increased total antioxidant capacity and decreased activity of the malondialdehyde in the blood [69]. Studies on ethanolic extract of Brazilian

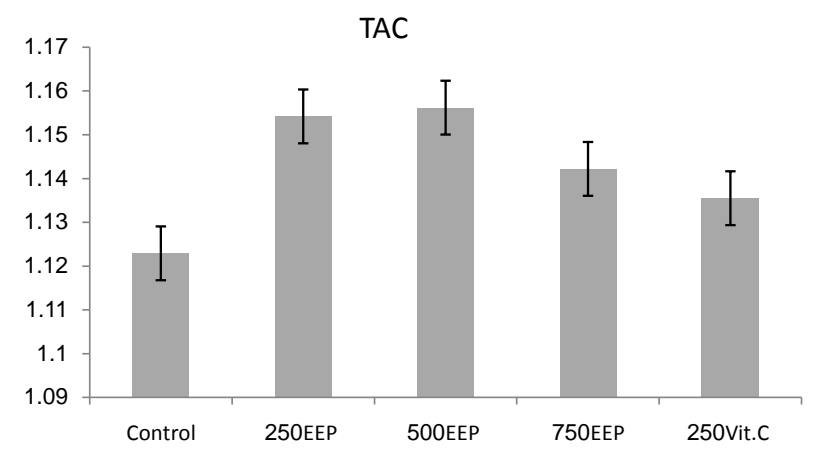

(a)

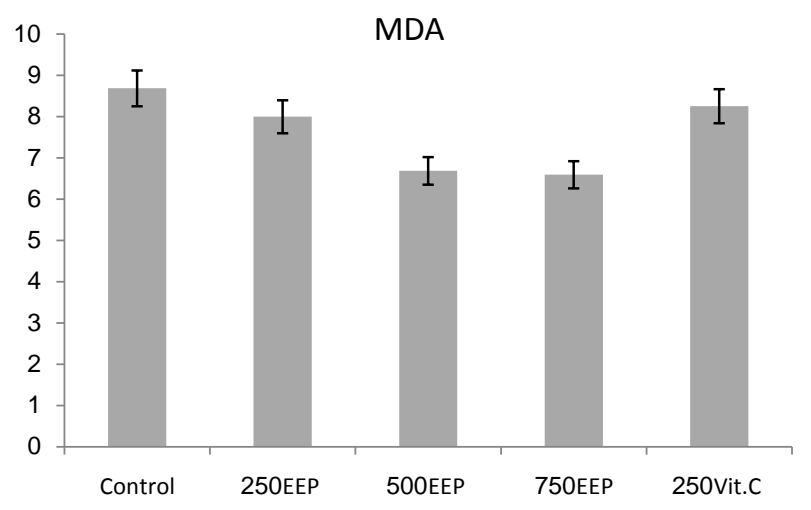

(b)

Figure 3. Effect of Chinese EEP (250, 500 and $750 \mathrm{mg} / \mathrm{kg}$ diet) and vit C (250 mg/kg diet) on (a) total Antioxidant capacity and (b) malondialdehyde activities in broilers exposed to heat stress. abc: means with different letters are significantly different $(P<0.05)$. 
propolis exerted antioxidant activity by inhibiting lipid peroxidation and by scavenging reactive oxygen species (ROS) in rats. That is possibly due to artepillin C., although a high dose of propolis reduced the protective effect possibly by enhancing the sensitivity to stress response [59]. In addition, the scavenging activity against superoxide anion radical of water extract Brazilian propolis was very strong even at concentrations lower than that of ascorbic acid [70]. According to De Sá et al., 2013 [71] propolis from Brazil (Guarapari) could be considered as a promising antioxidant product due to three main reasons: a) it contributes to protect membrane lipids from $\mathrm{H}_{2} \mathrm{O}_{2}$ stress; b) in response to an $\mathrm{O} 2 \bullet-$-stress mediated by menadione, propolis acts maintaining the redox status by scavenging ROS and c) it activates $\mathrm{Cu} / \mathrm{Zn}$-superoxide dismutase, one of the most important antioxidant enzymes.

\subsection{Bioactive Compounds of Chinese EEP and Antioxidant Activity}

Phenolic compounds either alone or in combination with other active ingredients was reported to be responsible for the antioxidant activity of propolis. Ethanol extracts of propolis collected from various climate and orographic characteristics, from Italy, Brazil and Russia had a higher antioxidant power due to higher content of polyphenols [72]. Also, propolis samples from Canada demonstrated significant radical scavenging activity against DPPH, due to the high concentrations of phenolic compounds: p-coumaric acid and its esters and hydroxyacetophenone and dihydrochalcones [73].

Phenolic compounds (flavonoids and phenolic acid derivatives) were the most important active constituents in Chinese EEP (Table 1). Because of the diversity and complexity of the natural mixtures of bioactive compounds in the propolis extract, it is rather difficult to characterize every compound present and elucidate its structure in a single study. The major flavonoids detected from EEP in our study were, flavanone, pinobanksin, galangin, kaempferol, pinobanksin acetate, luteolin and chalcone. However, a small amount of phenolic acid and esters include p-cinnamic acid, 6-Cinnamylchrysin, propenoic acid ester were also identified. So, we observed some similarities in the qualitative composition between Chinese EEP in our study and European and Argentinean propolis; the most abundant compounds were chrysin $(2 \%-4 \%)$, pinocembrin $(2 \%-4 \%)$, pinobanksin acetate (1.6\% - 3\%), and galangin (1\% - 2\%) [74]. The biological activities of the European-type propolis (popular type) which collected not only in Europe but also in China and other countries [75] are mainly due to flavonones, flavones, phenolic acids, and their esters [76].

The present study, as denoted from chemical analysis of propolis bioactive components, flavonoids (flavanone, 5,7-dihydroxy, mono-TMS and 3-O-[(S)-2-Methylbutyroyl] pinobanksin) constitute about $72.3 \%$ of the total compounds which could be responsible for the excellent antioxidant activities obtained. Because flavonoids are the most abundant and most effective antioxidants in propolis [77] [78]; Gardana et al., 2007 [74] suggested taking the total flavonoid content as a quality index. Propolis with a content less than $11 \%$ should be considered of low quality, whereas propolis with a content of $11 \%-14 \%, 14 \%-17 \%$, or $>17 \%$ should be classified as propolis of acceptable, good, and high quality, respectively. Thus, accordingly, Chinese EEP used in this study was a high quality grad because flavonoid content was higher than $17 \%$.

Analysis of propolis by Volpi and Bergonzini, 2006 [79] had a great amount of pinocembrin flavonoid (63\%), but no presence of genistein, kaempferol, apigenin, or chrysin for the sample from China. Another study about ethanol Chinese propolis identified other active components as rhamnetin, galangin, isoferulic acid, pinocembrin, chrysin, 5-methoxy-3,7-dihydroxyflavanone, apigenin, isorhamnetin and quercetin [70]. However, the major functional phenolic compounds in Chinese water extracted propolis (WEPs) were epicatechin, p-coumaric acid, morin, 3,4-dimethoxycinnamic acid, naringenin, ferulic acid, cinnamic acid, pinocembrin, and chrysin, which had strong antioxidant activities [80]. Most of those compounds could not be identified in EEP in our study, as some propolis samples are extracted more efficiently by water than by ethanol which is also, nontoxic, can be absorbed easily, and can prevent the side effects caused by alcohol in EEP [80].

Gregoris and Stevanato, 2010 [81] correlated polyphenol composition of ethanolic extracts of Venetian propolis with antioxidant activity due to caffeic acid and its derivatives caffeic acid phenethyl ester and 1,1-dimethylallylcaffeate. They demonstrated the importance of the existence of two ortho-hydroxyl groups in an aromatic ring such as in caffeic acid and its derivatives on the antioxidant activity. The presence of only one hydroxyl group or two meta-hydroxyl groups in the aromatic ring (pinocembrin and chrysin) contributed to a low inhibition of lipid peroxidation. The antioxidant activity of propolis may due to the ability of phenolic compounds to donate hydrogen ions that can attack the free radicals to prevent the oxidation reactions in the cell [82]. 
Furthermore, the mechanisms of flavonoid as antioxidant action can include 1) suppression of ROS formation either by inhibition of enzymes or by chelating trace elements involved in free radical generation; 2) scavenging ROS; and 3) up-regulation or protection of antioxidant defenses [83] [84]. The occurrence, position, structure, and total number of sugar moieties in flavonoid (flavonoids glycosides) play an important role in antioxidant activity [85].

Italian propolis mainly constituted by flavonoids and had possessed high antioxidant ability [86]. However, ethyl acetate extracts of propolis from several Algerian regions show high activity by scavenging free radicals, preventing lipid peroxidation and inhibiting myeloperoxidase (MPO) which could be contributed to polyphenols and flavonoids (kaempferol) and other compounds such as cinnamic acid and the combination of these compounds appears to be important to have the best antioxidant properties that prevent the damage produced by oxidative stress [87] (Boufadi et al., 2014).

The presence of diverse phenolic compounds, although dissimilar in different samples, is a good explanation for the antioxidant activity of propolis from different geographic origin [73]. This difference between the bioactive compounds responsible for antioxidant activities may be due to the qualitative and quantitative differences in their physico-chemical compositions [88]. In addition, geographic areas [89], the local flora and plant species in the region [90], the season of harvesting [91], the availability of water and the climate [87] and the solvents used in extraction [80] were key factors influencing the total phenolic content of the propolis.

The study suggested that Chinese EEP had a strong antioxidant activity in broilers exposed to chronic heat stress at summer season in Egypt. The recommended dose for Chinese EEP applied was $500 \mathrm{mg} / \mathrm{kg}$ diet which could alleviate the hormonal and metabolic drawbacks of heat stress; indicated by lowest corticosteron level and maximum total antioxidant and malondialdehyde capacity in broilers.

\section{Acknowledgements}

The authors are grateful to Dr. Usama T. Mahmoud, Lecturer of Animal Behavior and Management, Department of Animal Hygiene, Faculty of Veterinary Medicine, Assiut University for his great effort during the course of this experiment.

\section{References}

[1] Attia, Y., Al-Hanoun, A. and Bovera, F. (2011) Effect of Different Levels of Bee Pollen on Performance and Blood Profile of New Zealand White Bucks and Growth Performance of Their Offspring during Summer and Winter Months. Journal of Animal Physiology and Animal Nutrition, 95, 17-26.

[2] Gross, W.B. and Siegel, H.S.C. (1983) Evaluation of the Heterophil/Lymphocyte Ratio as a Measure of Stress in Chickens. Avian Diseases, 27, 972-979.

[3] Siegel, H.S. (1995) Stress, Strains and Resistance. British Poultry Science, 36, 3-22.

[4] Yegani, M. (2008) Summer and Heat Stress. http://www.worldpoultry.net/Home/General/2008/6/Summer-and-heat-stress-WP003006W

[5] Quinteiro-Filho, W.M., Rodrigues, M.V., Ribeiro, A., Ferraz-de-Paula, V., Pinheiro, M.L., Sa, L.R., Ferreira, A.J. and Palermo-Neto, J. (2012) Acute Heat Stress Impairs Performance Parameters and Induces Mild Intestinal Enteritis in Broiler Chickens: Role of Acute HPA Axis Activation. Journal of Animal Science, 90, 1986-1994.

[6] Siegel, H.S. (1980) Physiological Stress in Birds. BioScience, 301, 529-533.

[7] Beuving, G., Jones, R.B. and Blokhuis, H.J. (1989) Adrenocortical and Heterophil/Lymphocyte Responses to Challenge in Hens Showing Short or Long Tonic Immobility Reactions. British Poultry Science, 30, 175-184.

[8] Ligeiro de Oliveira, A.P., Lazzarini, R., Cavriani, G., Quinteiro-Filho, W.M., Tavares de Lima, W. and Palermo-Neto, J. (2008) Effects of Single or Repeated Amphetamine Treatment and Withdrawal on Lung Allergic Inflammation in Rats. International Immunopharmacology, 8, 1164-1171.

[9] Hayashi, K., Nagai, Y., Ohtsuka, A. and Tomita, Y. (1994) Effects of Dietary Corticosterone and Trilostane on Growth and Skeletal Muscle Protein Turnover in Broiler Cockrels. British Poultry Science, 35, 789-798.

[10] Kumar, S., Ajeet, K. and Meena, K. (2011) Review Effect of Heat Stress in Tropical Livestock and Different Strategies For Its Amelioration. Journal of Stress Physiology \& Biochemistry, 7, 45-54.

[11] Sies, H. (1991) Oxidative Stress: From Basic Research to Clinical Application. The American Journal of Medicine, 91, 31-38. http://dx.doi.org/10.1016/0002-9343(91)90281-2

[12] Nagai, T., Sakai, M., Inoue, R., Inoue, H. and Suzuki, N. (2001) Antioxidative of Some Commercially Honeys, Royal 
Jelly and Propolis. Food Chemistry, 75, 237-240. http://dx.doi.org/10.1016/S0308-8146(01)00193-5

[13] Melo, E.A., Maciel, M.I.S., Lima, V.L.A.G., Leal, F.L.L., Caetano, A.C.S. and Nascimento, R.J. (2006) Capacidade antioxidante de hortaliças usualmente consumidas. Ciência e Tecnologia de Alimentos, 26, 639-644. http://dx.doi.org/10.1590/S0101-20612006000300024

[14] Ardestani, A. and Yazdanparast, R. (2007) Antioxidant and Free Radical Scavenging Potential of Achillea santolina Extracts. Food Chemistry, 104, 21-29. http://dx.doi.org/10.1016/j.foodchem.2006.10.066

[15] Sharififar, F., Moshafi, M.H., Mansouri, S.H., Khoshademas, M. and Koshinoodi, M. (2006) In Vitro Avaluation of Antibacterial and Antioxidant Activities of the Essential Oil and Methanol Extracts of Endemic Zataria multiflora Boiss. Food Control, 18, 800-805. http://dx.doi.org/10.1016/j.foodcont.2006.04.002

[16] Tatli Seven, P., Yilmaz, S., Seven, I., Cerci, I.H., Azman, M.A. and Yilmaz, M. (2009) Effect of Propolis on Selected Blood Indicators and Antioxidant Enzyme Activities in Broilers under Heat Stress. Acta Veterinaria Brno, 78, 75-83. http://dx.doi.org/10.2754/avb200978010075

[17] Sahin, N., Onderci, M., Sahin, K., Gursu, M.F. and Smith, M.O. (2004) Ascorbic Acid and Melatonin Reduces Heat Induced Performance Inhibition and Oxidative Stress in Japanese Quails. British Poultry Science, 45, 116-122. http://dx.doi.org/10.1080/00071660410001668941

[18] Halliwell, B. (1991) Reactive Oxygen Species in Living Systems: Source, Biochemistry, and Role in Human Disease. The American Journal of Medicine, 91, 14-22. http://dx.doi.org/10.1016/0002-9343(91)90279-7

[19] Tatli Seven, P., Yilmaz, S., Seven, I. and Tuna Kelestemur, G. (2012) The Effects of Propolis in Animals Exposed Oxidative Stress. In: Lushchak, V.I., Ed., Oxidative Stress—Environmental Induction and Dietary Antioxidants, Chap. 13, InTECH BOOK, Rijeka, 267-288.

[20] Tatli Seven, P., Seven, I., Yilmaz, M. and Simsek, G. (2008) The Effects of Turkish Propolis on Growth and Carcass Characteristics in Broilers under Heat Stress. Animal Feed Science and Technology, 146, 137-148. http://dx.doi.org/10.1016/j.anifeedsci.2007.11.003

[21] Seven, I., Aksu, T. and Seven, P.T. (2010) The Effects of Propolis on Biochemical Parameters and Activity of Antioxidant Enzymes in Broilers Exposed to Lead-Induced Oxidative Stress. Journal of Animal Science, 23, 1482-1489.

[22] Varaprasad Reddy, L.S.S., Leela, V., Sudhakara Reddy, B. and Ananda Reddy, P. (2014) A Study of the Effect of Vitamin C and Ocimum sanctum Supplementation on Antioxidant Enzyme Levels in Broilers under Heat-Stress. International Journal of Veterinary Health Science \& Research, 2, 21-23.

[23] Choi, J.Y., Peña, I.C., Yoon, S.Y., Woo, T.S, Choi, Y.J., Shin, C.Y., Ryn, J.H., Lee, Y.S., Yu, G.Y. and Cheong, J.H. (2011) Is the Anti-Stress Effect of Vitamin C Related to Adrenal Gland Function in Rat. Food Science and Biotechnology, 20, 429-435. http://dx.doi.org/10.1007/s10068-011-0060-3

[24] Mckee, J.S. and Hurrison, P.C. (1995) Effects of Supplemental Ascorbic Acid on the Performance of Broiler Chickens Exposed to Multiple Concurrent Stressors. Poultry Science, 74, 1772-1785. http://dx.doi.org/10.3382/ps.0741772

[25] Kumaran, A. and Karakumaran, J. (2007) In Vitro Antioxidant Activities of Methanol Extracts of Five Phyllanthus Species from India. LWT_Food Science and Technology, 40, 344-352. http://dx.doi.org/10.1016/j.lwt.2005.09.011

[26] Mosquera, O.M., Correra, Y.M. and Niño, J. (2009) Antioxidant Activity of Plant Extracts from Colombian Flora. Revista Brasileira de Farmacognosia, 19, 382-387. http://dx.doi.org/10.1590/S0102-695X2009000300008

[27] Valle, M.L. (2000) Quantitative Determination of Antibacterian Capacities of Propolis. Apiacta, 35, $152-161$.

[28] Türkez, H., Yousef, M.I. and Geyikoglu, F. (2010) Propolis Prevents Aluminum-Induced Genetic and Hepatic Damages in Rat Liver. Food and Chemical Toxicology, 48, 2741-2746. http://dx.doi.org/10.1016/j.fct.2010.06.049

[29] Khalil, M.L. (2006) Biological Activity of Bee Propolis in Health and Disease. Asian Pacific Journal of Cancer Prevention, 7, 22-31.

[30] Mohammadzadeh, S., Shariatpanahi, M., Hamedi, M., Ahmadkhaniha, M., Samadi, R. and Ostad, S.N. (2007) Chemical Composition, Oral Toxicity and Antimicrobial Activity of Iranian Propolis. Food Chemistry, 103, 1097-1103. http://dx.doi.org/10.1016/j.foodchem.2006.10.006

[31] Amoros, M., Simoes, C.M.O., Girre, L., Sauvager, F. and Cormier, M. (1992) Synergistic Effect of Flavones and Flavonols against Herpes Simplex Virus Type I in Cell Culture Comparison with the Antiviral Activity of Propolis. Journal of Natural Products, 55, 1732-1740. http://dx.doi.org/10.1021/np50090a003

[32] Dobrowolski, J.W., Vohoraq, S.B., Sharma, K., Shah, S.A., Naqvi, S.A.H. and Dandiya, P.C. (1991) Antibacterial, Antifungal, Antiamoebic, Antiinflammatory, and Antipyretic Studies on Propolis Bee Products. Journal of Ethnopharmacology, 35, 77-82. http://dx.doi.org/10.1016/0378-8741(91)90135-Z

[33] Banskota, A.H., Nagaoka, T., Sumioka, L.Y., Tezuka, Y., Awale, S., Midorikawa, K., Matsushige, K. and Kadota, S. (2002) Antiproliferative Activity of the Netherlands Propolis and Its Active Principles in Cancer Cells Lines. Journal of Ethnopharmacology, 80, 67-73. http://dx.doi.org/10.1016/s0378-8741(02)00022-3 
[34] Missima, F. and Sforcin, J.M. (2008) Green Brazilian Propolis Action on Macrophages and Lymphoid Organs of Chronically Stressed Mice. Evidence-Based Complementary and Alternative Medicine, 5, 71-75. http://dx.doi.org/10.1093/ecam/nel112

[35] Marcucci, M.C. (1996) Propriedades biológicas e terapêuticas dos constituintes químicos da própolis. Quimica Nova, 19, 529-536.

[36] Ahn, M., Kumazawa, S., Usui, Y., Nakamura, J., Matsuka, M., Zhu, F. and Nakayama, T. (2007) Antioxidant Activity and Constituents of Propolis Collected in Various Areas of China. Food Chemistry, 101, 1400-1409. http://dx.doi.org/10.1016/j.foodchem.2006.03.045

[37] Da Silva, J.F.M., Souza, M.C., Matta, S.R., Andrade, M.R. and Vidal, F.V.N. (2006) Correlation Analysis between Phenolic Levels of Brazilian Propolis Extracts and Their Antimicrobial and Antioxidant Activities. Food Chemistry, 99, 431-435. http://dx.doi.org/10.1016/j.foodchem.2005.07.055

[38] Choi, Y.M., Noh, D.O., Cho, S.Y., Suh, H.J., Kim, K.M. and Kim, J.M. (2006) Antioxidant and Antimicrobial Activities of Propolis from Several Regions of Korea. LWT_Food Science and Technology, 39, 756-761. http://dx.doi.org/10.1016/j.lwt.2005.05.015

[39] Basnet, P., Matsuno, T. and Neidlein, R. (1997) Potent Free Radical Scavenging Activity of Propol Isolated from Brazilian Propolis. Zeitschrift für Naturforschung, 52c, 828-833.

[40] Banskota, A.H., Tezuka, T., Adyana, I.K., Midorikawa, K., Matsushige, K., Message, D., Huertas, A.G.A. and Kadota, S. (2000) Cytotoxic, Hepatoprotective and Free Radical Scavenging Effects of Propolis from Brazil, Peru, the Netherlandas and China. Journal of Ethnopharmacology, 72, 239-246. http://dx.doi.org/10.1016/S0378-8741(00)00252-X

[41] Havsteen, B.H. (2002) The Biochemistry and Medical Significance of the Flavonoids. Pharmacology \& Therapeutics, 96, 67-202. http://dx.doi.org/10.1016/S0163-7258(02)00298-X

[42] Tatli Seven, P. (2008) The Effects of Dietary Turkish Propolis and Vitamin C on Performance, Digestibility, Egg Production and Egg Quality in Laying Hens under Different Environmental Temperatures. Asian-Australasian Journal of Animal Sciences, 21, 1164-1170. http://dx.doi.org/10.5713/ajas.2008.70605

[43] Seven, İ., Tatli Seven, P. and Silici, S. (2011) Effects of Dietary Turkish Propolis as Alternative to Antibiotic on Growth and Laying Performances, Nutrient Digestibility and Egg Quality in Laying Hens under Heat Stress. Revue de Médecine Vétérinaire, 162, 186-191.

[44] Ohkawa, H., Ohishi, N. and Yagi, K. (1979) Assay for Lipid Peroxides in Animal Tissues by Thiobarbituric Acid Reaction. Analytical Biochemistry, 95, 351-358. http://dx.doi.org/10.1016/0003-2697(79)90738-3

[45] Kumazawa, S., Hamasaka, T. and Nakayama, T. (2004) Antioxidant Activity of Propolis of Various Geographic Origins. Food Chemistry, 84, 329-339. http://dx.doi.org/10.1016/S0308-8146(03)00216-4

[46] NRP (1994) Nutrient Requirements of Poultry. Ninth Revised Edition, The National Academies of Sciences, Engineering, and Medicine, Washington DC. http://www.nap.edu/openbook.php?isbn=0309048923

[47] Bankova, V., Popova, M., Bogdanov, S. and Sabatini, A.G. (2002) Chemical Composition of European Propolis: Expected and Unexpected Results. Zeitschrift für Naturforschung, 57c, 530-533.

[48] Garriga, C., Hunter, R.R., Amat, C., Planas, J.M., Mitchell, M.A. and Moreto, M. (2006) Heat Stress Increases Apical Glucose Transport in the Chicken Jejunum. American Journal of Physiology-Regulatory, Integrative and Comparative Physiology, 290, R195-R201. http://dx.doi.org/10.1152/ajpregu.00393.2005

[49] Astolfi-Ferreira, C.S., Ferreira, A.J. and Palermo-Neto, J. (2012) Heat Stress Impairs Performance and Induces Intestinal Inflammation in Broiler Chickens Infected with Salmonella Enteritidis. Avian Pathology, 41, 421-427. http://dx.doi.org/10.1080/03079457.2012.709315

[50] Kutlu, H.R. and Forbes, J.M. (1993) Changes in Growth and Blood Parameters in Heat Stressed Broiler Chicks in Response to Dietary Ascorbic Acid. Livestock Production Science, 36, 335-350. http://dx.doi.org/10.1016/0301-6226(93)90050-R

[51] Mahmoud, U.T., Abdel-Rahman, M.A.M. and Darwish, M.H.A. (2014) Effects of Propolis, Ascorbic Acid and Vitamin E on Thyroid and Corticosterone Hormones in Heat Stressed Broilers. Journal of Advanced Veterinary Research, 4, 18-27.

[52] Quinteiro-Filho, W.M., Ribeiro, A., Ferraz-de-Paula, V., Pinheiro, M.L., Sakai, M., Sa, L.R., Ferreira, A.J. and Palermo-Neto, J. (2010) Heat Stress Impairs Performance Parameters, Induces Intestinal Injury, and Decreases Macrophage Activity in Broiler Chickens. Poultry Science, 89, 1905-1914. http://dx.doi.org/10.3382/ps.2010-00812

[53] Sujatha, V., Korde, J.P., Rastogi, S.K., Maini, S., Ravikanth, K. and Rekhe, D.S. (2010) Amelioration of Heat Stress Induced Disturbances of the Antioxidant Defense System in Broilers. Journal of Veterinary Medicine and Animal Health, 2, 18-28.

[54] Nockels, C.F., Lopez, G.A. and Phillips, R.W. (1973) Influence of Vitamin A and C on Corticosterone and Carbohy- 
drate Metabolism in Chickens. Poultry Science, 52, 1261-1269. http://dx.doi.org/10.3382/ps.0521261

[55] Sheila, K.S. and Cheryl, F.N. (1978) Effect of Age, Sex, and Ascorbic Acid Ingestion on Chicken Plasma Corticosterone Levels. Poultry Science, 57, 527-533. http://dx.doi.org/10.3382/ps.0570527

[56] Mckee, J.S., Harrison, P.C. and Riskowski, G.L. (1997) Effect of Supplemental Ascorbic Acid on the Energy Conversion of Broiler Chicks during Heat Stress and Feed Withdrawal. Poultry Science, 76, 1278-1286. http://dx.doi.org/10.1093/ps/76.9.1278

[57] Pagliarone, A.C., Orsatti, C.L., Búfalo, M.C., Missima, F., Bachiega, T.F., Araújo Jr., J.P. and Sforcin, J.M. (2009) Propolis Effects on Pro-Inflammatory Cytokine Production and Toll-Like Receptor 2 and 4 Expression in Stressed Mice. International Immunopharmacology, 9, 1352-1356. http://dx.doi.org/10.1016/j.intimp.2009.08.005

[58] Orsatti, C.L. and Sforcin, J.M. (2012) Propolis Immunomodulatory Activity on TLR-2 and TLR-4 Expression by Chronically Stressed Mice. Natural Product Research, 26, 446-453. http://dx.doi.org/10.1080/14786419.2010.482049

[59] Nakamura, T., Ohta, Y., Tada, M., Teruya, A., Ohashi, K., Ikeno, K., et al. (2011) Protective Effect of Brazilian Propolis Ethanol Extract against Stress Induced Gastric Mucosal Lesions in Rats. Its Evaluation Using Oxidative Stress Markers. Journal of Analytical Bio-Science, 34, 135-146.

[60] Lee, M., Kim, Y.H., Park, W., Ahn, W.G., Park, O.K., Kwon, S., Morita, K., Shim, I. and Her, S. (2013) Novel Antidepressant-Like Activity of Propolis Extract Mediated by Enhanced Glucocorticoid Receptor Function in the Hippocampus. Evidence-Based Complementary and Alternative Medicine, 2013, 1-10.

[61] Selem, A.S.M. (2012) Effect of Propolis on Ruminal Fermentation, Reproductive and Productive Performance of Santa Inês Ewes. PhD Thesis, Center of Nuclear Energy and Agriculture, San Poulo University, Piracicaba.

[62] Ohno, S., Satoshi, S., Satoshi, T., Hiroyuki, N, Tsunehisa, M. and Shizuo, N. (2002) Effect of Flavonoid Phytochemical on Cortisol Production and on Activities of Steroidogenic Enzyme in Human Adrenocortical H295R Cells. Journal of Steroid Biochemistry and Molecular Biology, 80, 355-363. http://dx.doi.org/10.1016/S0960-0760(02)00021-3

[63] Li, Y.J., Xuan, H.Z., Shou, Q.Y., Zhan, Z.G., Lu, X., and Hu, F.L. (2012) Therapeutic Effects of Propolis Essential Oil on Anxiety of Restraint-Stressed Mice. Human and Experimental Toxicology, 31, 157-165. http://dx.doi.org/10.1177/0960327111412805

[64] Abdel-Mohsein, H.S., Mahmoud, M.A.M. and Mahmoud, U.T. (2014) Influence of Propolis on Intestinal Microflora of Ross Broilers Exposed to Hot Environment. Advances in Animal and Veterinary Sciences, 2, 204-211. http://dx.doi.org/10.14737/journal.aavs/2014/2.4.204.211

[65] Temple, N.J. (2000) Antioxidants and Disease: More Questions than Answers. Nutrition Research, 20, 449-459. http://dx.doi.org/10.1016/S0271-5317(00)00138-X

[66] Frey, B. (1991) Vitamin C Protects Lipids in Human Plasma and Low Density Lipoprotein against Oxidative Damage. The American Journal of Clinical Nutrition, 54, 113.

[67] Agudelo, L.G. (1983) Possible Causes of Avian Oedema. International Journal of Poultry Sciences, 22, 8-14.

[68] Lutsenko, E.A., Carcamo, J.M. and Golde, D.W. (2002) Vitamin C Prevents DNA Mutation Induced by Oxidative Stress. The Journal of Biological Chemistry, 277, 16895-16899. http://dx.doi.org/10.1074/jbc.M201151200

[69] Hashem, N.M., AbdEl-Hady, A. and Hassan, O. (2013) Effect of Vitamin E or Propolis Supplementation on Semen Quality, Oxidative Status and Hemato-Biochemical Changes of Rabbit Bucks during Hot Season. Livestock Science, 157, 520-526. http://dx.doi.org/10.1016/j.livsci.2013.09.003

[70] Nagaia, T., Inoueb, R., Inoueb, H. and Suzuki, N. (2003) Preparation and Antioxidant Properties of Water Extract of Propolis. Food Chemistry, 80, 29-33. http://dx.doi.org/10.1016/S0308-8146(02)00231-5

[71] De Sá, R.A., de Castro, F.A.V., Eleutherio, E.C.A., de Souza, R.M., da Silva, J.F.M. and Pereira, M.D. (2013) Brazilian Propolis Protects Saccharomyces cerevisiae Cells against Oxidative Stress. Brazilian Journal of Microbiology, 44, 993-1000. http://dx.doi.org/10.1590/S1517-83822013005000062

[72] Fabris, S., Bertelle, M., Astafyeva, O., Gregoris, E., Zangrando, R., Gambaro, A., Lima, G.P.P. and Stevanato, R. (2013) Antioxidant Properties and Chemical Composition Relationship of Europeans and Brazilians Propolis. Pharmacology \& Pharmacy, 4, 46-51. http://dx.doi.org/10.4236/pp.2013.41006

[73] Christov, R., Trusheva, B., Popova, M., Bankova, V. and Bertrand, M. (2006) Chemical Composition of Propolis from Canada, Its Antiradical Activity and Plant Origin. Natural Product Research, 20, 531-536. http://dx.doi.org/10.1080/14786410500056918

[74] Gardana, C., Scaglianti, M., Pietta, P. and Simonetti, P. (2007) Analysis of the Polyphenolic Fraction of Propolis from Different Sources by Liquid Chromatography-Tandem Mass Spectrometry. Pharmaceutical and Biomedical Analysis, 45, 390-399. http://dx.doi.org/10.1016/j.jpba.2007.06.022

[75] Fujimoto, T., Nakamura, J. and Matsuka, M. (2001) Diversity of Propolis. Part 1. Propolis from the World. Honeybee Science, 22, 9-16. (In Japanese) 
[76] Bankova, V. (2005) Recent Trends and Important Developments in Propolis Research. Evidence-Based Complementary and Alternative Medicine, 2, 29-32. http://dx.doi.org/10.1093/ecam/neh059

[77] Bonvehi, J.S. and Coll, F.V. (1994) Phenolic Composition of Propolis from China and from South America. Zeitschrift Fur Naturforschung C-A Journal of Biosciences, 49, 712-718.

[78] Isla, M.I., Nieva, M.I., Sampietro, A.R. and Vattuone, M.A. (2001) Antioxidant Activity of Argentine Propolis Extracts. Journal of Ethnopharmacology, 76, 165-170. http://dx.doi.org/10.1016/S0378-8741(01)00231-8

[79] Volpi, N. and Bergonzini, G. (2006) Analysis of Flavonoids from Propolis by On-Line HPLC-Electrospray Mass Spectrometry. Pharmaceutical and Biomedical Analysis, 42, 354-361. http://dx.doi.org/10.1016/j.jpba.2006.04.017

[80] Guo, X., Chen, B., Luo, L., Zhang, X., Dai, X. and Gong, S. (2011) Chemical Compositions and Antioxidant Activities of Water Extracts of Chinese Propolis. Journal of Agricultural and Food Chemistry, 59, 12610-12616. http://dx.doi.org/10.1021/jf202818p

[81] Gregoris, E. and Stevanato, R. (2010) Correlations between Polyphenolic Composition and Antioxidant Activity of Venetian Propolis. Food and Chemical Toxicology, 48, 76-82. http://dx.doi.org/10.1016/j.fct.2009.09.018

[82] El Sohaimy, S.A. and Masry, S.H.D. (2014) Antioxidant and Antimicrobial Activities of Egyptian and Chinese Propolis. American-Eurasian Journal of Agricultural \& Environmental Sciences, 14, 1116-1124.

[83] Halliwell, B. and Gutteridge, J. (1998) Free Radicals in Biology and Medicine. Oxford University Press, Oxford.

[84] Mishra, A., Kumar, S. and Pandey, A.K. (2013) Scientific Validation of the Medicinal Efficacy of Tinospora cordifolia. The Scientific World Journal, 2013, Article ID: 292934. http://dx.doi.org/10.1155/2013/292934

[85] Kumar, S. and Pandey, A.K. (2013) Chemistry and Biological Activities of Flavonoids: An Overview. The Scientific World Journal, 2013, Article ID: 162750. http://dx.doi.org/10.1155/2013/162750

[86] Papotti, G., Bertelli, D., Bortolotti, L. and Plessi, M. (2012) Chemical and Functional Characterization of Italian Propolis Obtained by Different Harvesting Methods. Journal of Agricultural and Food Chemistry, 60, 2852-2862. http://dx.doi.org/10.1021/jf205179d

[87] Boufadi, Y.M., Soubhye, J., Riazi, A., Rousseau, A., Vanhaeverbeek, M., Nève, J., Boudjeltia, K.Z. and Van Antwerpen, P. (2014) Characterization and Antioxidant Properties of Six Algerian Propolis Extracts: Ethyl Acetate Extracts Inhibit Myeloperoxidase Activity. International Journal of Molecular Sciences, 15, 2327-2345. http://dx.doi.org/10.3390/ijms15022327

[88] Fonseca, Y.M., Marquele-Oliveira, F., Vicentini, F.T.M.C., Furtado, N.A.J.C., Sousa, J.P.B., Lucisano-Valim, Y.M. and Fonseca, M.J.V. (2011) Evaluation of the Potential of Brazilian Propolis against UV-Induced Oxidative Stress. Evidence-Based Complementary and Alternative Medicine, 2011, Article ID: 863917. http://dx.doi.org/10.1155/2011/863917

[89] Bankova, V.S., De Castro, S.L. and Marcucci, M.C. (2000) Propolis: Recent Advances in Chemistry and Plant Origin. Apidologie, 31, 3-15. http://dx.doi.org/10.1051/apido:2000102

[90] Savickas, A., Majiene, D., Ramanauskiene, K., Pavilonis, A., Muselik, J., Masteikova, R., et al. (2005) Chemical Composition and Antimicrobial Activity of Lithuanian and Czech Propolis. Biologija, 4, 59-63.

[91] Chen, Y.W., Wu, S.W., Ho, K.K., Lin, S.B., Huang, C.Y. and Chen, C.N. (2008) Characterization of Taiwanese Propolis Collected from Different Locations and Seasons. Journal of the Science of Food and Agriculture, 88, 412-419. http://dx.doi.org/10.1002/jsfa.3101 